\title{
Forage potential of wild populations of perennial ryegrass collected from southern New Zealand farms
}

K.H. WIDDUP and D.L. RYAN

AgResearch, Gore Research Centre, Private Bag 50022, Gore

\begin{abstract}
A ryegrass breeding programme to improve the cool season activity and summer quality of perennial ryegrass (Lolium perenne $\mathrm{L}$, ) in southern regions was initiated in 1986. One of the strategies assessed wild ryegrass populations from $\mathbf{5 0}$ dairy and sheep farms in Southland, West Otago and Westland. The plants were collected and evaluated as spaced plants in a high and low fertility site at DSIR Grasslands Gore in comparison with current ryegrass cultivars. Principal Component Analysis was used to order the performance of the ryegrass populations in relation to the observed characters of seasonal growth, tillering, crown rust infection, recurrent ear emergence and endophyte presence. The collection consisted of many short-leaved densely tillered prostrate plants with high levels of crown rust infection and recurrent flowering. In comparison the cultivars had fewer, but larger tillers, rapid leaf extension and good rust tolerance. There were no strong distinguishing features between plants from dairy and sheep farms and 30\% of plants had no endophyte. Selected ecotypes hybridised with New Zealand and European cultivars produced plants with better cool season growth and summer quality than standard cultivars. The ecotype germplasm is an important source in the development of new cultivars suited to the southern region.
\end{abstract}

Keywords plant evaluation, Lolium perenne, ryegrass hybrids, southem New Zealand ecotypes

\section{Introduction}

Perennial ryegrass (Lolium perenne L.) is the most important grass species in southern New Zealand pastures. It is well adapted to the cool, moist temperate climate and intensive grazing practices of the region. Growth potential and persistence of ryegrass are limited by low soil fertility conditions which are becoming more widespread as fertiliser inputs are reduced. The shortage of grass during winter/early spring restricts animal carrying capacity and affects animal performance. The decline in the quality of ryegrass during its seed-head phase and recurrent flowering is a major reason for reduced lamb growth rates (Ulyatt 1981).

Hence a breeding programme was initiated at DSIR Grasslands Gore to improve these limiting factors within perennial ryegrass. One of the strategies was to collect wild populations (ecotypes) of ryegrass from old pastures on farms of southern New Zealand. This paper describes the results of an evaluation of 50 farm populations. The survey compared this wild ecotype material with current ryegrass cultivars to identify ryegrass plants with cool-season growth, less recurrent flowering, resistance to crown rust (Puccinia coronata) and absence of endophyte (Acremonium lolii).

\section{Materials and methods}

Fifty ryegrass populations were collected from farms within the cool moist climatic regions of Southland and West Otago; (annual rainfall $900 \mathrm{~mm}$ to $1500 \mathrm{~mm}$ ) and Westland (1800 to $4800 \mathrm{~mm})$ during the spring of 1986. Within these regions ryegrass populations were collected from four types of farm. Seven populations came from low fertility sheep farms (Olsen $\mathrm{P}$ soil test 8 to 11); 28 from high fertility sheep farms; (Olsen $\mathrm{P}$ range 1535); 6 from cattle/sheep farms (Olsen $P$ 15-23) and 9 from dairy farms (Olsen P 20-60).

At each farm, a pasture considered productive and greater than 25 years old was sampled.' Sixty $50 \mathrm{~mm}$ diameter pasture cores were removed at random across the pasture. Each core was dissected and a single ryegrass plant removed. This plant was separated into individual tillers and two tillers of equal size were planted into separate soil pots to encourage further plant development before transplanting to the field. At the same time, seed from nine current ryegrass cultivars was sown in pots.

The first set of plants from the 50 populations was planted in a high fertility site with $\mathrm{pH} 5.8$ and Olsen $\mathrm{P} 18$; potassium $(\mathrm{K})$ and sulphur $(\mathrm{S})$ were 6 and $5 \mathrm{ppm}$ respectively. The second set were planted in a low fertility site with pH 5.3, Olsen P 8, K and $\mathbf{S} 3$ and 2 ppm, respectively, at AgResearch, Gore in November 1986. Each site had previously been treated with glyphosphate to remove resident ryegrasses while leaving the legume base intact. The high fertility site was maintained with an annual dressing of $300 \mathrm{~kg} / \mathrm{ha}$ potassic superphosphate (O-7-15-7); the low fertilitysitereceivednofertiliser. At 
each site the $\mathbf{5 0}$ wild populations and the $\mathbf{9}$ current cultivars were randomised in 6 blocks. Each population and cultivar in a block consisted of a row with 10 plants at $50 \mathrm{~cm}$ spacings.

Seasonal growth, tiller density, growth habit, leaf extension, crown rust infection and recurrent ear emergence were noted for each plant-on a visual scale. The presence or absence of endophyte was determined by sampling 30 plants of each population in summer. After each plant character assessment, at 4- to 6-weekly intervals during spring and summer, twice during the autumn and at the end of winter, the plants were grazed with sheep.

Principal Component Analysis (PCA) was used to arrange ecotypes and cultivars into recognisable groups based on overall performance in the trials. The analysis of the 50 ecotypes and cultivar means for the various measured characters allowed a multitude of related variables to be replaced by a few derived variables or principal components. When plotted the components

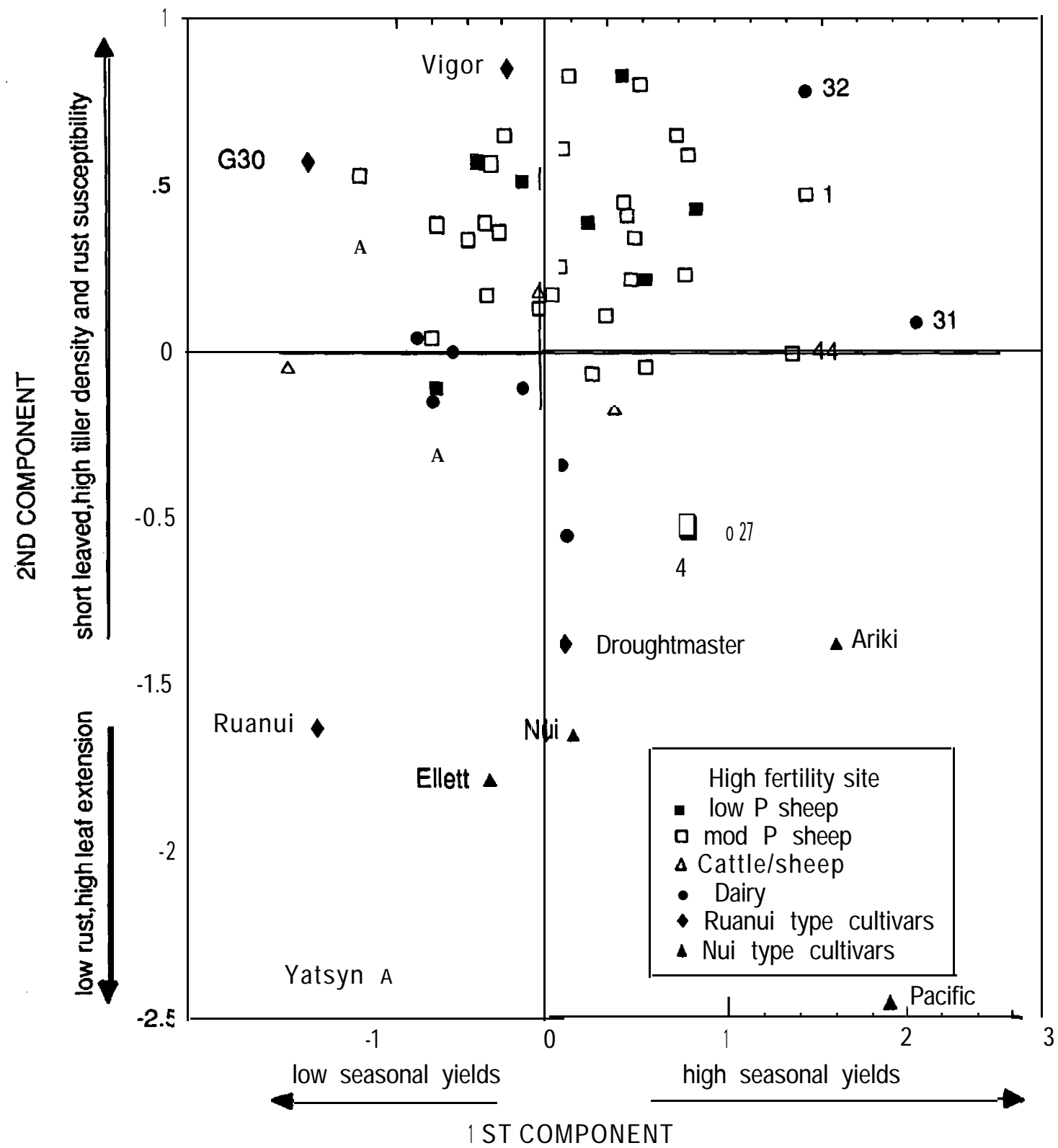

Figure 1 Position of the 50 wild populations of ryegrass and the $9 \mathrm{NeW}$ Zealand cultivars as defined by the principal components 1 and 2. in the high fertility site. 
portray the relative performance of all ryegrass populations.

\section{Results}

The seasonal herbage yields and morphological features oftheryegrassecotypesandcultivarsinthehighandlow fertility sites are presented in Figures 1 and 2 respectively. Under both fertility sites $80 \%$ of the total variation was explained by the first two principal compo- nents. The first component (x-axis) in both figures was positively correlated to plants with consistent high yields in spring, summer and autumn in each of the 3 years that they were observed towards the right side the graph and poor yielding plants on the left side of the graph. The second component (y-axis) represents densely tillered plants which were short-leaved and rust susceptible towards the top end of the graph. Plants with good leaf extension, larger leaved and rust tolerant were at the lower end of the axis.

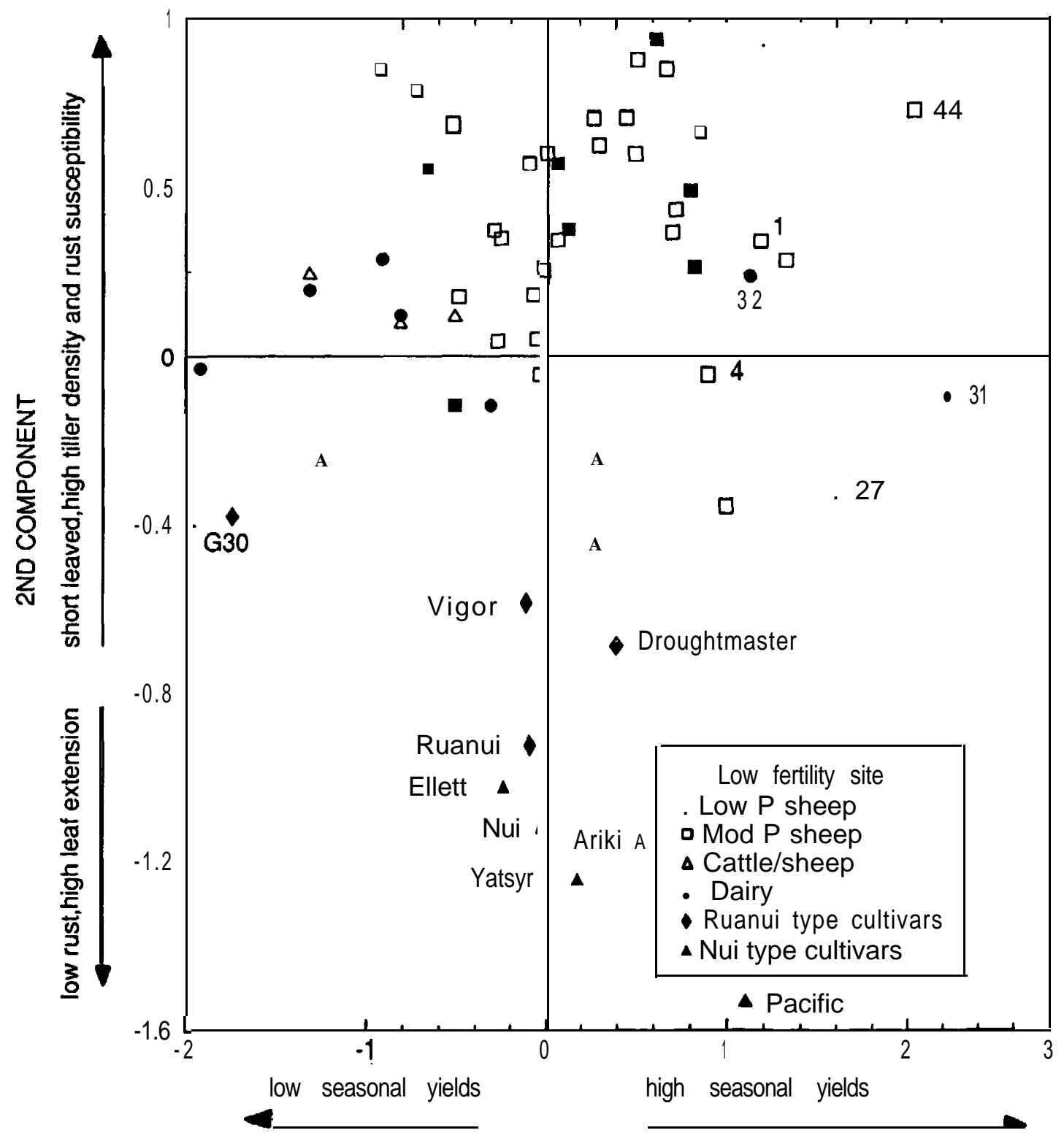

I S T COMPONENT

Flgure 2 Position of the 50 wild populations of ryegrass md 9 New Zealand cultivars as defined by the principal components 1 and 2 in the low futility site. 
The ecotypes formed a distinct set, different to the New Zealand bred cultivars (Figures 1 and 2). They were densely tillered plants which were short leaved and susceptible to crown rust. The ecotypes were uniformly early heading and all developed reproductive heads between 9 and 20 November which is similar to the heading time of standard New Zealand cultivars. However $62 \%$ of the ecotype plants had recurrent flowering intosummercompared withfortypercentof thecultivar plants. Vigor (a European cultivar) and G30 (North Island hill country selection) had similar features to the ecotypes. The remaining seven New Zealand cultivars had fewer but larger tillers, rapid leaf extension and good rust tolerance compared with the ecotypes.

Inboththehighandlow fertility sitesthefourgroups of ecotypes showed little differentiation when plotted (Figures 1 and 2) and merged together regardless of where they originated. There was no interactionbetween the high and low fertility evaluation sites as those ecotypes with high growth (Lines 1,4,27,31,32 and 44) were the best at either fertility site. The four groups of ecotypes were also represented by high and low yielding populations which were consistent in both fertility sites.

In the ecotype populations, $70 \%$ of the plants were endophytic and $30 \%$ of plants had nil endophyte. In one

Table 1 Percentage of endophytic plants in the ecotype population

\begin{tabular}{lccccc}
\hline Endophyte Level \% & $0-20$ & $21-40$ & $41-60$ & $61-80$ & $81-100$ \\
number of populations & 2 & 6 & 13 & 13 & 16
\end{tabular}

quarter of the populations less than $50 \%$ of the plants wereendophytic (Table 1).Themostproductiveecotype populations (Lines 1, 4. 27, 31,32 and 44) showed variable numbers of endophytic plants: $87 \%$. 96\%. $26 \%$ $37 \% \quad 52 \%$ and $66 \%$ respectively. Plant growth was compared during the second summer in the high fertility site (Table 2). The infected and uninfected plants followed a normal distribution for growth with a similar percentage of plants at each growth score.

Selected ecotype plants were hybridised with plants from New Zealand and European cultivars which had

Table 2 Summer growth in the second year of ecotype plants with or without endophyte

\begin{tabular}{lcc}
\hline Summer growth score & $\begin{array}{c}\text { \% Endophytic } \\
\text { plants }\end{array}$ & $\begin{array}{c}\text { \% non endophytic } \\
\text { plants }\end{array}$ \\
\hline 1 poor & 11 & 10 \\
2 & 17 & 17 \\
3 average & 33 & 35 \\
4 & 25 & 23 \\
5 excellent & 13 & 14 \\
\hline
\end{tabular}

rust resistance and less recurrent heading. The hybrid lines were evaluated as spaced plants and showed improvedgrowthinall seasons whencomparcdtostandard cultivars (Table 3). The hybrids with European parentage had better summer growth, were more leafy and densely tillered than other hybrids.Hybrids with New Zealand parentage had superior autumn/winter and spring growth compared to the standard cultivsrs.

\section{Discussion}

The southern New Zealand perennial ryegrass collection showed little discrete differentiation between ecotypes in plant morphology and during the reproductive phase. Even though the collection came from both dairy and sheep farms under high and low fertility soil conditions, the four groups of ecotypes had no strong distinguishing features. This result is consistent with collections made in the North Island (Suckling \& Forde 1978; Wedderburn et al. 1989) where sampling from a wide range of environments did not reveal distinct ryegrass ecotypes.

The ecotype plants when viewed as a whole collection, were densely tillered. prostrate growing type plants with relatively short leaves. During summer a large proportion of the collection put a significant amount of energy into the reproductive phase with continuous recurrent flowering and seed setting. Thesemorphological andreproductive characteristics are adaptive mechanisms to ensure plant survival under intense grazing management practices and other harsh environmental conditions. The standard cultivars contrasted strongly with the ecotypes. They had fewer tillers, grew more upright and were longer leaved, flowering was confined hugely to a narrower time span and less recurrent flowering occurred. These features are seen by plant breeders as desirable for animal production under rotational grazing conditions.

The ecotype populations showed differences in herbage yield potential. These differences were not specifically linked to any one of the four stock and fertility groupings, previously outlined. Theresponse pattern for herbage yields showed a number of ecotype populations (Figures 1 and 2) which were inherently high yielding in both high and low soil fertility. The converse was also true, with consistently low yielding ecotypepopulations under both fertility conditions. Superior plants were selected mainly from the numbered populations (Figures 1 and 2) which had inherently the highest yielding response pattern.

The varying numbers of endophytic plants within theecotypepopulations contrasts sharply with the North Island hill country collection of Wedderbum et al. (1989) and the North Island collection of Cooper (pers. wmm.) where $85-100 \%$ of their plants contained endo- 
Table 3 Pefformance of selected ecotypes hybridised with New Zealand and European ryegrass cultivass. (mean of two years).

\begin{tabular}{|c|c|c|c|c|c|c|c|}
\hline \multirow[t]{2}{*}{ Hybrids } & \multirow{2}{*}{$\begin{array}{l}\text { Number } \\
\text { of lines }\end{array}$} & \multicolumn{3}{|c|}{ Growth Score } & \multicolumn{3}{|c|}{ Morphology } \\
\hline & & Spring & Summer & AutWint & Tillering & Leaflness & $\begin{array}{l}\text { Leaf } \\
\text { length }\end{array}$ \\
\hline $\begin{array}{l}\text { Ecotype X European cultivars } \\
\text { Ecolype X Ecotype }\end{array}$ & $\begin{array}{c}6 \\
13\end{array}$ & $\begin{array}{l}3.2 \\
3.1\end{array}$ & $\begin{array}{l}3.3 \\
3.0\end{array}$ & $\begin{array}{l}3.3 \\
3.2\end{array}$ & $\begin{array}{l}3.0 \\
2.6\end{array}$ & $\begin{array}{l}3.3 \\
2.7\end{array}$ & $\begin{array}{l}2.6 \\
3.0\end{array}$ \\
\hline $\begin{array}{l}\text { Ecotype X NZ cultivars } \\
\text { Control_cultivars }\end{array}$ & 22 & 3.2 & 3.0 & 3.3 & 2.4 & 2.5 & 3.0 \\
\hline Nul types & 7 & 2.7 & 2.6 & 2.6 & 1.6 & 1.6 & 3.2 \\
\hline Ruanui types & 4 & 2.4 & 2.3 & 2.4 & 2.0 & 2.0 & 2.2 \\
\hline LSD $(5 \%)$ & & 0.4 & 0.4 & 0.4 & 0.4 & 0.4 & 0.3 \\
\hline
\end{tabular}

phyte. The presence of endophyte ensures the survival of a plant by conferring resistance to the pest Argentine stem weevil (Listronotus bonariensis (Kuschel)). The cooler and wetter summer conditions of the southern regions do not favour the development of significant population levels of Argentine stem weevil and therefore allows a significant number of $\mathrm{ml}$ endophyte plants to persist. If the vigour of the nil endophyte plants was being hindered. a skewed distribution to lower growth scores would be expected. Thii result indicates that selecting high yielding nil-endophyte plants will have a distinctadvantageforproducinghighlambgrowthrates in southern regions (Eerens et al. 1992; Fletcher $\boldsymbol{e t}$ al. 1990).

Many ecotypeplants with good cool-season growth, high tiller numbers and absence of endophyte were identified; however. most were highly rust susceptible and had recurrent ear emergence. Both these factors are detrimental to ryegrass quality over summer when there is a need for high quality forage to sustain high lamb growth rates. Germplasm with leafy summer growth and little recurrent flowering has been identified in $\mathrm{Eu}-$ ropean cultivars (Widdup \& Ryan 1993). New Zealand cultivars contain plants with good cool season growth and rust resistance.

The hybridiiation of superior ecotypes with superiorNew Zealand and Europeanplantmaterialproduced plants with improved cool season yields and summer quality factors compared to the standard cultivars. The ecotype collection has proved to be an interesting and valuable source in the development of new genetic material. This material will form the basis of cultivars adapted to the climate, topography and grazing management systems of the region.

\section{ACKNOWLEDGEMENTS}

We thank Kerryn Miller and Deborah Allan for technical assistance with the evaluation.

\section{REFERENCES}

Eerens, J.P.J.; Ryan, D.L.; Miller, K.B. 1992. The ryegrass endophyte in a cool moist environment, Proceeding of New Zealand Grassland Association 54: this vol.

Fletcher, L.R.; Hoglund, J.H.; Sutherland B.L. 1990. The impact of Acremonium endophytes in New Zealand, past, present and future. Proceedings of the New Zealand Grassland Association 52: 227-235.

Suckling, F.E.T.; Forde. M.B. 1978. Genetic resources in high rainfall hill pastures of New Zealand. New Zealand journal of agricultural research 21: 499-508.

Ulyatt, M.J. 1981. The feeding value of herbage; can it be improved? NewZealandAgricultural science IS: 200-20s.

Wedderbum. M.E.; Pengelly. W.J.; Tucker, M.A.; di Menna, M.E. 1989. Description of ryegrass removed from New Zealand North Island hill country. New Zealand journal of agricultural research 32: 521-529.

Widdup, K.H.; Ryan, D.L. 1993. Potential of European perennial ryegrass germplasm in Southern New Zealand. Proceedings of XVII International Grassland Congress. 